\title{
Editorial
}

\section{The continuing scourge of human rabies in south and southeast Asia}

Canine rabies has been endemic in south and southeast Asia since time immemorial. Many thousand human deaths are reported annually from this region [1]. We have the knowledge to eradicate human rabies [2]. This is reinforced by published International guidelines [3-5]. Any real gains in reducing human rabies deaths, at least in Thailand, have come from providing "state of the art" post exposure prophylaxis for animal bit victims and not by control of this dreaded disease in the dog vectors. This is not hindering continuing expansion of rabies to previously free regions in Asia such as Flores, Moluku, Bali, and Nias in Indonesia. At least one international conference is convened annually in Asia by WHO, academics or international organizations in efforts to start effective canine rabies control programs. Lack of bureaucratic motivation, funding, ignorance and cultural barriers have hindered any real sustained success.

The editors of Asian Biomedicine invited a written historical review of what has and has not been done in the past for canine rabies eradication worldwide. Merritt Cliffton, editor of "Animal People", is a recognized historian in this field. We are grateful for his contribution but also recognize that he may be somewhat controversial; being one of a leaders of the large international animal welfare organizations. His priority, quite correctly, is a humane approach to dog population control. This is required to achieve sustainability and manageability. He is not an extremist, like some who might place animal over human lives. Such radical groups have done serious damage to public health in some countries. We believe that Merrit Clifford does recognize the need for some culling of dogs, but only in selected situations when necessary and by humane means. We believe that he is aware that some canine population reduction is required to make sustainable vaccination logistically feasible. This will require education of the public and new technology for dog birth control; particularly in canine rabies endemic regions where surgical sterilization of large numbers of stray dogs is not possible. We have, again, reached a point where WHO and others are discussing long term plans to eradicate rabies in Asia. These culminated in June of 2011 at a WHO consultative conference at Bangkok, attended by leading Asian workers in this field. All participants from Asia and WHO agreed that sustainable vaccination of a manageable total dog population is the only choice. For new intensive efforts to eradicate canine rabies in Asia, we will need the cooperation of governments, the population and also of the animal welfare community. Understanding and learning from history should also help us not to repeat past mistakes. It is a challenging project with many barriers to overcome. Most are well illustrated in Merritt Clifton's essay and also in a recent publication by the same author [6].

\section{References}

1. Miranda E. Epidemiology of Rabies in Asia.WHO Global Vaccine Research Forum. WHO 2006.

2. Rabies. $2^{\text {nd }}$ edition, Editors AC Jackson and Wm H Wunner. Elsevier, Amsterdam. 2007.

3. Rabies. $2^{\text {nd }}$ WHO Strategies for the control and elimination of rabies in Asia. WHO/CDS/ CSR/EPH/ 2002.8 Geneva 2001.

4. Rabies Vaccines. WHO weekly Epi Position Paper. 2010; 32:309-20.

5. WHO. Guidelines for dog rabies control. WHO, Geneva. VPH/8.

6. WHO. Guidelines for dog population management WHO, Geneva ZOON/90.166.

7. Merritt Clifton, How not to fight a rabies epidemic. Asian Biomed. 2010; 4:663-70. 